\title{
Welcome to the TBV EUMASS special issue for the XXIInd EUMASS Congress of Insurance Medicine in Maastricht!
}

\author{
Gert Lindenger
}

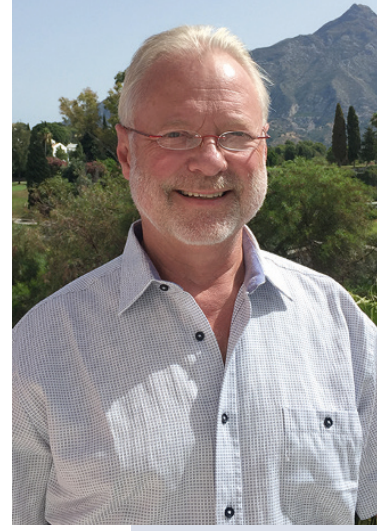

Gert Lindenger, President of EUMASS
EUMASS (the European Union of Medicine in Assurance and Social Security) is an organisation aiming to follow and spread scientific knowledge and 'good practice' in Insurance Medicine in Europe. It consists of 20 European countries that all have national organisations that are involved in Insurance Medicine. Since 1974, EUMASS has been organising a congress every other year to facilitate the exchange of experiences within the field of insurance medicine mainly focusing on public social security. This year, insurance physicians from all over Europe will gather at a venue in Maastricht. Twelve plenary lectures will be given, together with 140 parallel presentations, making it the largest event organised in the field of Insurance Medicine.

Insurance physicians from all over Europe gathering at a venue such as in Maastricht also provides a platform where colleagues can meet and discuss; it is an important occasion for the exchange of opinions between the European insurance-related organisations.
It has been a privilege to cooperate with the Dutch Journal of Occupational and Insurance Medicine (Tijdschrift voor Bedrijfs- en Verzekeringsgeneeskunde - TBV on this special issue on EUMASS in English, with contributions from several EUMASS member countries. Social Insurance is a vital part of the welfare systems across Europe and it can have a significant impact on its citizens. Decisions need to be based on objective medical facts as far as possible in order to gain legal confidence and the public's respect. Unbiased medical reasoning is essential. Therefore not only organised events where we meet at a venue, such as the congress, are important, but also other means such as professional associations, universities, scientific institutions and, last but not least, a professional journal in this field, such as the TBV. Therefore EUMASS warmly welcomes the initiative of TBV's special English issue on Insurance Medicine. they see each other only once every two years...
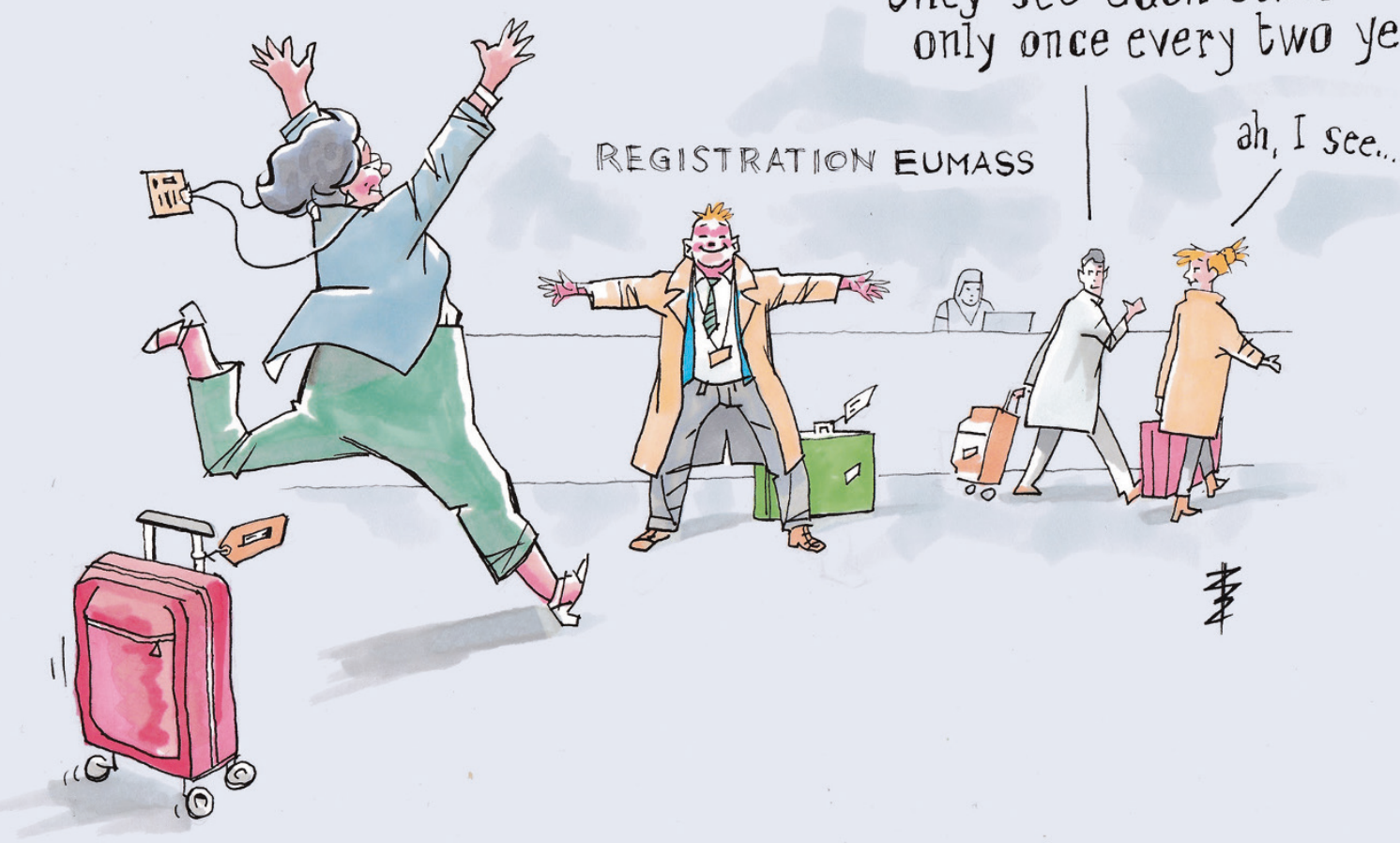